\title{
Our experience of the novel "flexible stylet method" for insertion of PD catheter in eight high-risk patients
}

\author{
Hiroyuki Terawaki ${ }^{1 *}$, Naotaro Fukushima ${ }^{1}$, Keiko Aoyagi ${ }^{1}$, Aya Nakajima', Masaaki Nakayama ${ }^{2}$ \\ and Tomokazu Karino ${ }^{3}$
}

\begin{abstract}
Background: Perforation of intra-abdominal organs such as the bowel and urinary bladder is one of the most serious complications related to peritoneal dialysis catheter (PDC) insertion procedures. Such a risk increases in patients with a history of prior abdominal surgery or irradiation. The "alpha-replacer" is a unique wire that is usually soft, but becomes harder if coiled in the hand. Application of this equipment as a stylet might improve the safety and effectiveness of PDC insertion.

Case presentation: A total of eight high-risk patients (organic adhesion, bleeding tendency, poor cardiac function, or malnutrition, or some of these) underwent a new peritoneal dialysis catheter (PDC) insertion procedure named "flexible stylet method" using alpha-replacer as a stylet. As a consequence, the maneuver was completed successfully in all patients and neither patient developed any major complications.
\end{abstract}

Conclusions: The novel "flexible stylet method" as described herein offers effective and safe treatment.

Keywords: Peritoneal dialysis, Catheter implantation, Less invasive, Alpha replacer, High risk cases

\section{Background}

Perforation of intra-abdominal organs such as the bowel and urinary bladder is one of the most serious complications related to the peritoneal dialysis catheter (PDC) insertion procedure [1]. Such a risk increases in patients with a history of prior abdominal surgery or irradiation. Although the risk of perforation is lower in open surgical insertion than in the blind or modified Seldinger technique [2], the risk of organ perforation is not completely avoidable if a hard stylet is used. Although the use of laparoscopic assistance lessens the risk of organ perforation [3], such beneficence of laparoscopy cannot be received by high-risk cases to which application of general anesthesia is impossible.

To make PDC catheter insertion procedures less invasive, we have developed a PDC insertion technique "flexible stylet method" using a unique equipment "alpha-

\footnotetext{
* Correspondence: terawaki@fmu.ac.jp

${ }^{1}$ Dialysis Center, Fukushima Medical University School of Medicine,

Fukushima, Japan

Full list of author information is available at the end of the article

replacer" as a stylet, and applied this new technique to high-risk patients.

\section{Case presentation}

A total of eight patients underwent "flexible stylet method" surgery at Fukushima Medical University Hospital. Patients' profiles are summarized in Table 1. All patients were regarded that an application of standard surgery using hard stylet or laparoscopic approach under general anesthesia was unfavorable because of at least one of these reasons: (1) bleeding tendency (cases 1, 2, 4, 6), (2) suspected organic adhesion caused by prior abdominal surgery or irradiation (cases 2, 3, 5, 7, 8), (3) impaired cardiac function (cases 1, 2, $4,5,6$ ), and (4) severe malnutrition represented by hypoalbuminemia $(\leq 3.0 \mathrm{~g} / \mathrm{dL})$ (cases $4,6,7)$.

\section{Details of flexible stylet method Alpha-replacer}

The alpha-replacer, which is developed in the late 1990s (JMS Co., Ltd., Tokyo, Japan, English homepage; http://www.jms.cc/english/index.html), is described in 
Table 1 Patients' profile

\begin{tabular}{|c|c|c|c|c|}
\hline Case & Age & Gender & Primary CKD & Comorbidity \\
\hline \multirow[t]{7}{*}{1} & 83 & $\mathrm{~F}$ & Cardiorenal syndrome type 2 & Bronchial asthma: since 62 years old \\
\hline & & & & Necrosis of left knee joint: 73 years old \\
\hline & & & & Stenosis of lumber spinal canal: since 75 years old \\
\hline & & & & Chronic heart failure: since 77 years old \\
\hline & & & & Pacemaker implantation for sick sinus syndrome: 79 years old \\
\hline & & & & Idiopathic thrombocythemia: since 80 years old \\
\hline & & & & Non-functioning parathyroid tumor: since 81 years old \\
\hline \multirow[t]{8}{*}{2} & 82 & M & Cardiorenal syndrome type 2 & Pemphigoid: since 55 years old \\
\hline & & & & Replacement of mitral and aortic valves: 56 years old \\
\hline & & & & Endoscopic mucosal resection for sigmoid cancer: 64 years old \\
\hline & & & & Chronic heart failure: since 72 years old \\
\hline & & & & Pelvic irradiation (70 Gy in total) for rectal cancer: 74 years old \\
\hline & & & & Hepatitis B virus-related liver cirrhosis: since 75 years old \\
\hline & & & & Constrictive pericarditis: since 81 years old \\
\hline & & & & Pacemaker implantation for bradycardiac atrial fibrillation: 81 years old \\
\hline \multirow[t]{4}{*}{3} & 81 & $\mathrm{~F}$ & Nephrosclerosis & Total hysterectomy for uterine myoma: 40 years old \\
\hline & & & & Diabetes mellitus and hypertension: since 54 years old \\
\hline & & & & Right oophorectomy for right ovarian cancer: 70 years old \\
\hline & & & & Left cerebral ischemic stroke: 81 years old \\
\hline \multirow[t]{4}{*}{4} & 68 & M & IgA nephropathy & Initiation of hemodialysis: 48 years old \\
\hline & & & & Atrial fibrillation: since 65 years old \\
\hline & & & & Bleeding tendency due to liver cirrhosis: since 66 years old \\
\hline & & & & Massive ascites due to liver cirrhosis: since 67 years old \\
\hline \multirow[t]{3}{*}{5} & 63 & M & Chronic glomerulonephropathy & Partial hepatectomy (donor of liver transplantation): 53 years old \\
\hline & & & & Left inguinal hernia surgery: 62 years old \\
\hline & & & & Impaired cardiac function due to undetermined etiology: since 63 years old \\
\hline \multirow[t]{5}{*}{6} & 67 & M & Myeloma kidney & Chronic heart failure: since 57 years old \\
\hline & & & & Bleeding tendency due to warfarin usage: since 57 years old \\
\hline & & & & Multiple myeloma accompanying AL amyloidosis: since 62 years old \\
\hline & & & & Implantation surgery of implantable cardiovascular defibrillator: 65 years old \\
\hline & & & & Severe orthostatic hypotension: since 66 years old \\
\hline \multirow[t]{3}{*}{7} & 79 & M & Diabetic nephropathy & Bilateral peroneal nerve palsy: 60 years old \\
\hline & & & & Hemorrhagic stroke: 70 years old \\
\hline & & & & Abdominal wall hernia surgery: 73 years old \\
\hline 8 & 71 & M & Diabetic nephropathy & Open cholecystectomy for cholecystolithiasis: 35 years old \\
\hline
\end{tabular}

our previous report [4]. Briefly, the unique feature of the alpha-replacer is that this metal wire is usually soft, but becomes harder if coiled in the hand (Additional file 1). Such unique characteristic of alpha-replacer, or difference to ordinary guide-wire, is owing to its structure: The alpha-replacer comprises an inside "rope" and peripheral "spring" structure (Fig. 1). Precise detail regarding structure and characteristics of alpha-replacer is described elsewhere [4]. In Japan, alpha-replacer is widely used as a special wire-type equipment for transluminal replacement of a displaced peritoneal catheter.

\section{Insertion procedure}

First, (a) a soft alpha-replacer covered with a PDC is inserted into the abdomen (Fig. 2). Next, (b) the wire is further inserted toward the Douglas pouch under fluoroscopic guidance. Then, (c) the alpha-replacer is slightly coiled in the hand, and the PDC is inserted following 


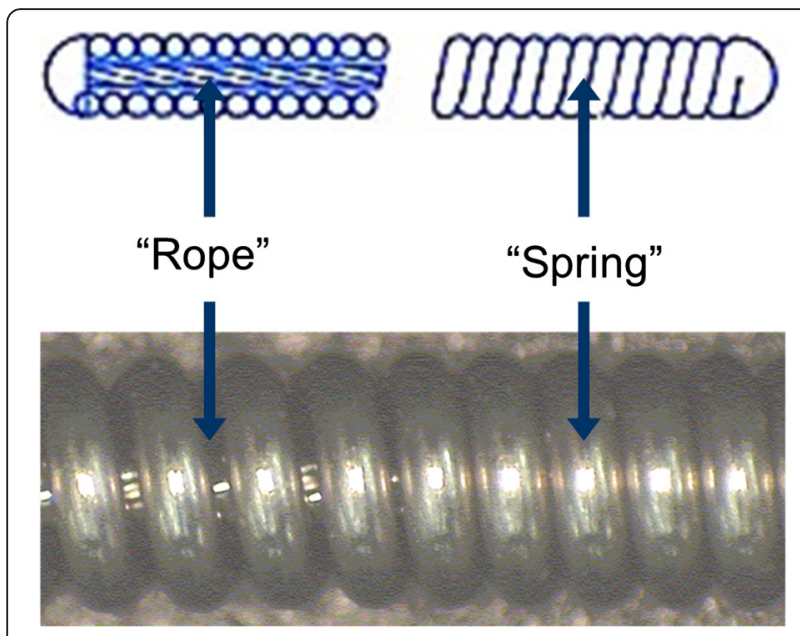

Fig. 1 The structure of alpha-replacer. The alpha-replacer comprises an inside "rope" and peripheral "spring" structure

the slightly hardened wire. Procedures (b) and (c) are repeated alternately until the PDC tip is placed into the rectouterine pouch (Fig. 3). The representative maneuver (using simulator instead of real patient) is shown in Additional file 2, and real surgical field (of case 1) is shown in Additional file 3.

\section{Consequence}

The maneuver was completed successfully in all patients within 5 min except for case 7 (15 min) whose bowel adhesion was severe. Neither of the patients complained of pain during the procedure. After operation, the PDC tip was confirmed to be in the correct position in the Douglas pouch using abdominal X-ray in all cases (Fig. 4).
In all cases, exchange of peritoneal dialysate was started the next day of PDC insertion. Temporal bloody effluent was observed for a few days in case 2. Besides, no complications were developed in all cases. After PDC insertion, the exchange of peritoneal dialysate was undergone without any trouble in all cases: neither dialysate leakage nor peritonitis was observed. All patients were discharged from the hospital after they mastered manipulation regarding peritoneal fluid exchange (6 to 37 days after PDC insertion).

\section{Discussion}

In this report, we adapted the new technique named "flexible stylet method" for the insertion of PDC to ESRD patients with high risks (organic adhesion, bleeding tendency, poor cardiac function, or malnutrition, or some of these). As a result, we completed successful maneuver without any severe complication.

The flexible stylet method described herein is considered superior to that using a hard stylet with regard to at least three points. The first point is safety. As alphareplacer is very soft when the equipment itself is inserted toward the minor pelvic space (for alpha-replacer is not hardened at this timing), the risk of organ injury can be minimized. In fact, bowel injury due to alpha-replacer usage has not been reported until now $[4,5]$. The second point is effectiveness. Although a fluoroscopically guided PDC insertion procedure using a fine guide-wire has already been reported [6, 7], the use of alphareplacer that can be hardened when needed offers us more accurate placement of the PDC tip into the minor pelvic space. The third point is the simplicity of the procedure, as described herein.

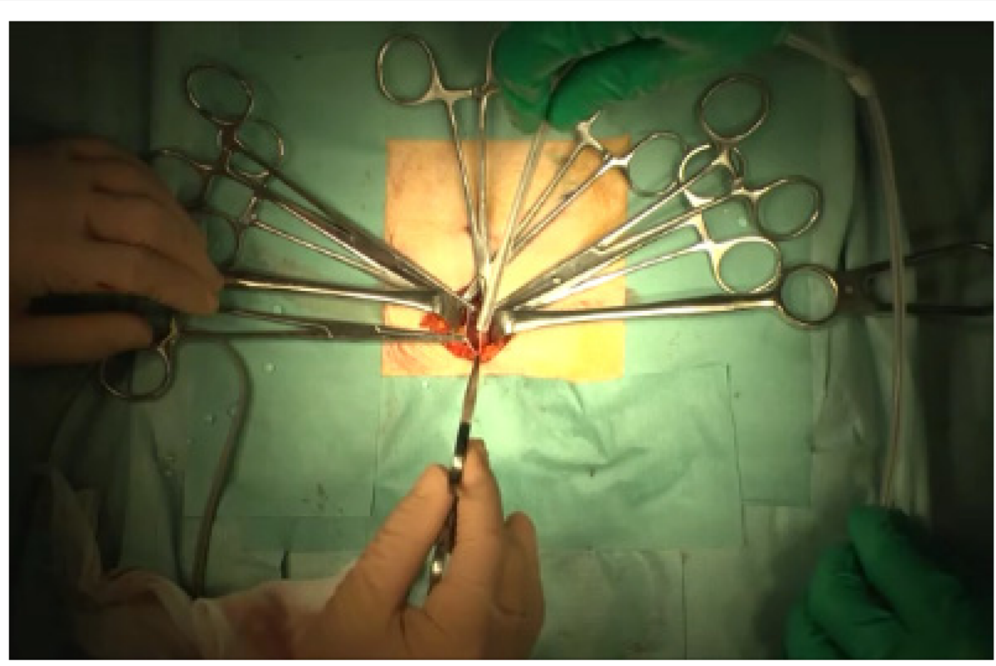

Fig. 2 PDC insertion procedure using the alpha-replacer as stylet. a Flexible alpha-replacer is covered with PDC. b PDC is inserted into the peritoneal cavity 

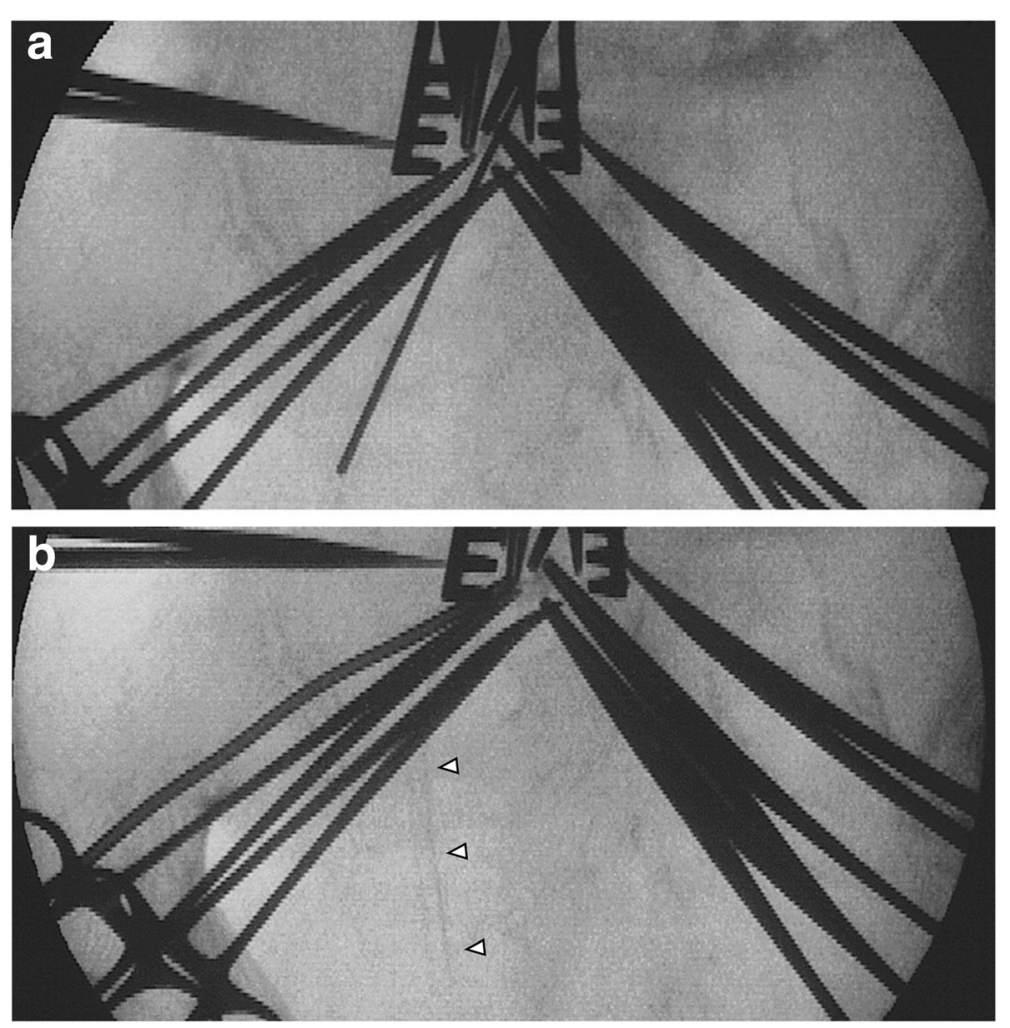

Fig. 3 Fluoroscopic image during PDC implantation (case 4). a PDC, accompanied by the alpha-replacer, is in the correct position in the minor pelvic space. b PDC after removal of the alpha-replacer. The PDC tip is in the correct position in the minor pelvic space (arrowhead)

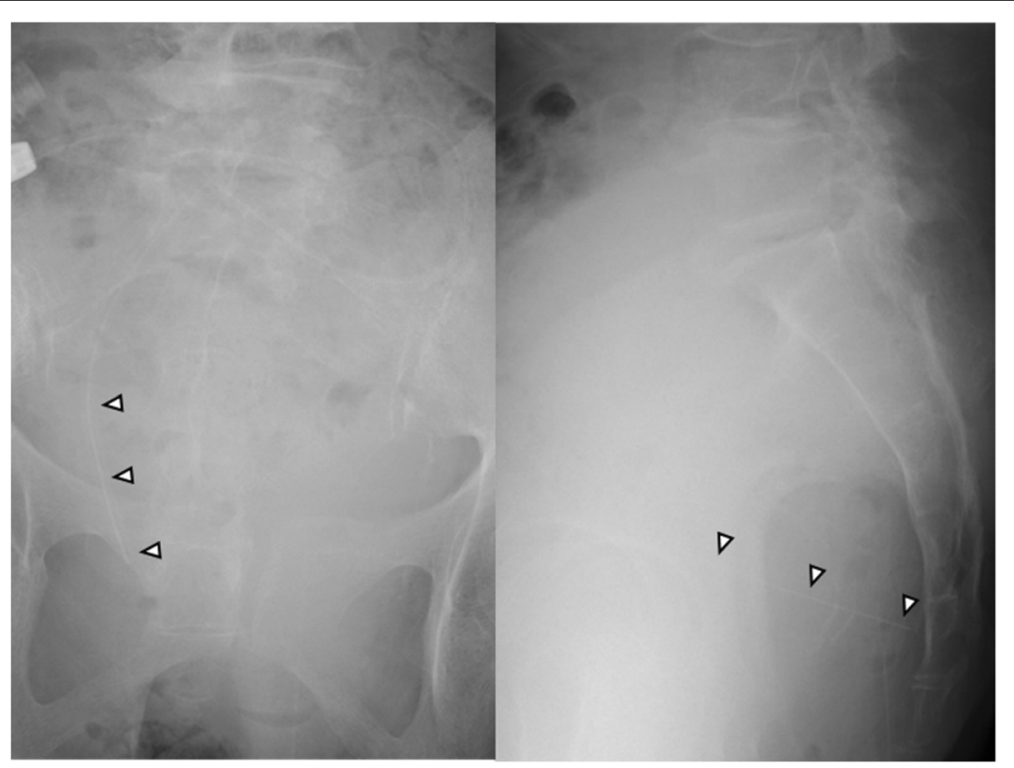

Fig. 4 Representative radiography of peritoneal catheter after PDC implantation (case 1). The PDC tip is in the correct position in the Douglas pouch (arrowhead) 
The alpha-replacer is a unique equipment developed specifically for transluminal replacement of a displaced $\mathrm{PDC}$, and has a double-spiral structure that confers unique characteristics to the equipment [4]. By coiling this in the hand, the free tip becomes hard, and release allows the free tip to become soft (Additional file 1). Proper adaptation of such characteristics in procedures should improve both the safety and success rate of PDC implantation.

The flexible stylet method is considered safe, effective, and simple. However, some limitations regarding this method remain. The first limitation is radiation exposure for fluoroscopic guidance. The second limitation is the somewhat complexity for the staffs of theater. The third limitation involves indications. We applied the present method to limited high-risk cases only. However, from the viewpoint of safety management, the flexible stylet method might be applied also to moderate or normal risk cases. The fourth and most important limitation is that the number of treated patient is relatively small (eight patients). The incidence of perforations reported in previous report is about 0.7 to $2.6 \%$ (one complication versus 40 to 140 PDC insertion) [8]. Thus, larger number of patient might be required to prove "real" incidence of perforations regarding this flexible method.

As the mean age of ESRD patients initiated dialysis therapy is increasing year by year [9], potential risk concerning PDC insertion is thought to be also increasing. We believe that flexible stylet method contributes to wide utilization of peritoneal dialysis therapy in the era of an aging ESRD population.

\section{Conclusions}

In conclusion, the flexible stylet method as described herein offers effective and safe treatment, especially for high-risk cases.

\section{Acknowledgements}

We thank Thermo Co. (Tokyo, Japan) and Mrs. Kaoru Terawaki for the assistance of videotaping (appendices 1 and 2).

\begin{abstract}
Authors' contributions
HT made substantial contributions to the stabilization of the present procedure. NF made technical contributions to stabilize the present procedure. KA, AY, MN, and TK helped to draft the manuscript. All authors read and approved the final manuscript submitted for publication.
\end{abstract}

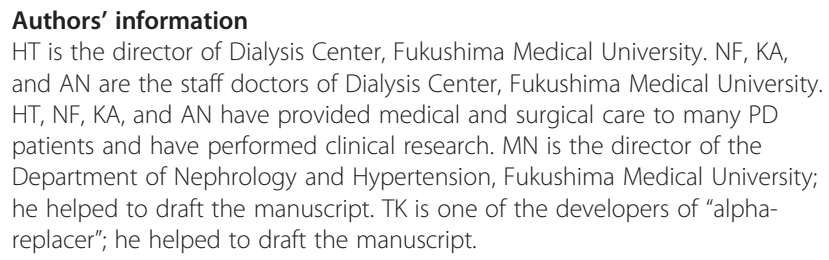
and AN are the staff doctors of Dialysis Center, Fukushima Medical University. $H T, N F, K A$, and AN have provided medical and surgical care to many PD patients and have performed clinical research. MN is the director of the Department of Nephrology and Hypertension, Fukushima Medical University; he helped to draft the manuscript. TK is one of the developers of "alphareplacer"; he helped to draft the manuscript.

\section{Competing interests}

The authors declare that they have no competing interests.

\section{Author details}

'Dialysis Center, Fukushima Medical University School of Medicine, Fukushima, Japan. ${ }^{2}$ Department of Nephrology and Hypertension, Fukushima Medical University School of Medicine, Fukushima, Japan. ${ }^{3}$ Research and Development, JMS Co., Ltd, Tokyo, Japan.

Received: 28 September 2015 Accepted: 20 August 2016

Published online: 20 November 2016

\section{References}

1. Rotellar C, Sivarajan S, Mazzoni MJ, Aminrazavi M, Mosher WF, Rakowski TA, et al. Bowel perforation in CAPD patients. Perit Dial Int. 1992;12:396-8.

2. Rana TA, Cramp H, Akoh JA. Evaluation of medical insertion of peritoneal dialysis catheters. Int J Nephrol Urol. 2011;3:46-53.

3. Ögünç G. A new laparoscopic technique for CAPD catheter placement. Perit Dial Int. 1999;19:493-4.

4. Terawaki H, Nakayama M, Nakano H, Hasegawa T, Ogura M, Hosoya T, et al, Transluminal replacement of displaced peritoneal catheter using a special "alpha-replacer" guidewire: effectiveness and limitations. Perit Dial Int. 2007;27:702-6.

5. Saka Y, Ito $Y$, lida $Y$, Maruyama S, Matsuo S. Efficacy and safety of fluoroscopic manipulation using the alpha-replacer for peritoneal catheter malposition. Clin Exp Nephrol. 2005;19:521-6.

6. Zaman F, Pervez A, Atray NK, Murphy S, Work J, Abreo KD. Fluoroscopyassisted placement of peritoneal dialysis catheters by nephrologists. Semin Dial. 2005;18:247-51.

7. Moon JY, Song S, Jung KH, Park M, Lee SH, Ihm CG, et al. Fluoroscopically guided peritoneal dialysis catheter placement: long-term results from a single center. Perit Dial Int. 2008;28:163-9.

8. Abreo K, Sequeira A. Bowel perforation during peritoneal dialysis catheter placement. Am J Kidney Dis DOl: http://dx.doi.org/10.1053/j.ajkd.2016.01.010 (in press)

9. Nakai S, Hanafusa N, Masakane I, Taniguchi M, Hamano T, Shoji T, et al. An overview of regular dialysis treatment in Japan (as of 31 December 2012). Ther Apher Dial. 2014;18:535-602.

Submit your next manuscript to BioMed Central and we will help you at every step:

- We accept pre-submission inquiries

- Our selector tool helps you to find the most relevant journal

- We provide round the clock customer support

- Convenient online submission

- Thorough peer review

- Inclusion in PubMed and all major indexing services

- Maximum visibility for your research 